\title{
Spectrophotometric Quantification of Iron in Different Pharmaceuticals
}

\author{
Kshama Parajuli*1, Kamala Sharma ${ }^{1}$, Narayan Bhattarai ${ }^{2}$, Ganga G.C ${ }^{3}$ \\ ${ }^{1}$ Central Department of Chemistry, Tribhuvan University, Kirtipur, Kathmandu, Nepal \\ ${ }^{2}$ Prithvi Narayan Campus, Pokhara, Nepal, ${ }^{3}$ Tri-Chandra Multiple Campus, Kathmandu, Nepal \\ *Corresponding E-mail: kshamaparajuli@gmail.com \\ (Received: October 5, 2020; Revised: January 22, 2021; \& Accepted: January 22, 2021)
}

\begin{abstract}
Quantification of iron in different pharmaceuticals can be performed by different analytical methods. In this study, a rapid, sensitive and simple spectrophotometric method was used for the determination of iron (II) in different iron tablets. A spectrophotometric method is based on the reaction of iron (II) with 1,10-phenanthroline to form an orange-red chelating complex in an acidic medium. The maximum absorbance of the chelating complex was measured at $510 \mathrm{~nm}$. The Beer Lambert's law was found to be obeyed in the range of 0.4-4.0 mg/L of iron (II). Out of ten samples analyzed, the observed amount of iron (II) in nine samples were range from 105 to $96 \mathrm{mg}$ whereas in one sample it was observed only $81 \mathrm{mg}$ per $100 \mathrm{mg}$ of the labeled amount of iron(II) by the manufacturer. Thus the results obtained by the spectrophotometric method using 1,10-phenanthroline as a color developing agent were nearly equal to the claimed values of iron (II) in different iron tablets from manufacturing companies.
\end{abstract}

Keywords: Iron, pharmaceuticals, a spectrophotometric method, 1,10-phenanthroline, Beer Lambert's law

\section{Introduction}

Iron, a chemical element with the symbol Fe and atomic number 26 is a metal in the first transition series which is the most abundant metal by mass found in the Earth [1-2]. It is also found in water as well as in different foodstuff and the human body naturally [2-3]. Iron is considered an essential nutrient as it is required for several vital functioning of the human body which includes oxidative metabolism, reproduction, cellular growth, wound healing and oxidation of various metabolic processes, etc. The main role of iron is to carry oxygen to the tissue where it is needed [4-5]. It is also essential for the proper functioning of numerous enzymes involved in DNA synthesis, energy metabolism, and protection against microbes and free radicals [6]. Besides, iron is also necessary to maintain healthy cells, skin, hair, nails, etc [7].

The amount of iron needed each day depends on age, gender, and overall health. Infants and toddlers require more iron than adults in general because their bodies are growing so quickly. Also, women need more iron because they lose blood each month during their period [8-9]. The average adult human body contains 3 to 4 grams of iron. About 60 to 70 percent of total iron is present in the hemoglobin of red blood corpuscles
(RBC) of the human body as circulating iron [10]. Iron deficiency anemia, a reduction in the hemoglobin concentration of oxygen-carrying capacity of the blood is characterized by loss of appetite, abdominal pains, tiredness, pale skin, cold hand and feet, brittle nail, shortness of breath and headaches, etc [11]. It may result from lack of iron in the diet, inadequate absorption from the gut, or losses, usually through bleeding [12].

Iron deficiency anemia is a leading cause for anemia globally affecting more than 2 billion people worldwide [13]. Also, about two-thirds of pregnant women suffer from iron deficiency anemia in the south Asian countries, which is the highest prevalence in the world [14]. In the central plains of Nepal, more than half of infants are anemic (hemoglobin concentration $<110 \mathrm{~g} / \mathrm{L}$ ) by 12 weeks of age. Furthermore, data indicate that more than threequarters of preschool children are anemic, with more than 3\% severely anemic (hemoglobin concentration $<70 \mathrm{~g} / \mathrm{L})$ [15].

Supplementation with iron tablets is the most widely used approach to control the global problem of iron deficiency anemia. However, unlike some supplements, when the intake of iron is excess it can be harmful to infants and young children. These 
effects include decreased growth, increased morbidity, impaired development, etc. Besides, iron overdose can damage the liver, brain, and heart which may lead to a heart attack or stroke [16-17]. Therefore, it is more important to understand taking iron supplements can have serious health consequences if unnecessarily consumed. Hence it is very important not only to make sure that only recommended amount of iron is taken but also to know whether the iron content is consistent as claimed by pharmaceutical companies.

The determination of metal ions at the trace level is one component in the field of pharmaceutical analysis. However, their analysis in the pharmaceutical preparation is challenging due to complex composition and a wide range of concentrations, which may vary from $\mathrm{ppb}$ to percent levels [18]. Although many sensitive and selective analytical methods such as chemiluminescence, graphite furnace atomic absorption spectrometry, flame atomic absorption spectrometry, fluorometric analysis, anodic stripping voltammetry, volumetric analysis, and spectrophotometry, etc are available for the determination of metal ions and most of these methods are very expensive for routine analysis of metal ions. Among them, a spectrophotometric method is well-established techniques and owing to their speed, selectivity, reduced implementation costs, the versatility of applications and therefore it can be considered to be the advantageous alternatives to sophisticated and expensive techniques normally used in the pharmaceutical analysis [19].

\section{Materials and Methods}

All the chemicals used in this study were of analytical grade (AR) or laboratory-grade (LR) reagents which were directly used without further purification. The stock iron solution (40 ppm iron(II)) was prepared by dissolving the required amount of Mohr's salt (AR, Merck) in $1 \mathrm{~mL} 98 \% \mathrm{H}_{2} \mathrm{SO}_{4}$. Similarly, 0.01M 1,10-phenanthroline (AR, Merck), Hydroquinone (0.1M) (AR, Merck), Sodium Citrate (0.1M) (LR, Qualigens), $\mathrm{HCl}$ (6M) (LR, Qualigens) solutions were prepared by taking a suitable amount of respective reagents in distilled water.

Ten different samples of antianemic drugs by different pharmaceutical companies at solid dosage form were collected by random sampling technique from the different medical stores of Thapathali, Kathmandu and were analyzed by using a spectrophotometric method as described elsewhere [20-21]. In brief, iron from iron tablets is reduced to $\mathrm{Fe}^{2+}$ with reducing agents such as hydroquinone and the ferrous ion chelates with 1,10-phenanthroline forming a stable complex of the orange-red color $\left[\mathrm{Fe}\left(\mathrm{C}_{12} \mathrm{H}_{8} \mathrm{~N}_{2}\right)_{3}\right]^{2+}$ (figure 1). The intensity of this color is proportional to the concentration of iron and follows Beer Lambert's law.

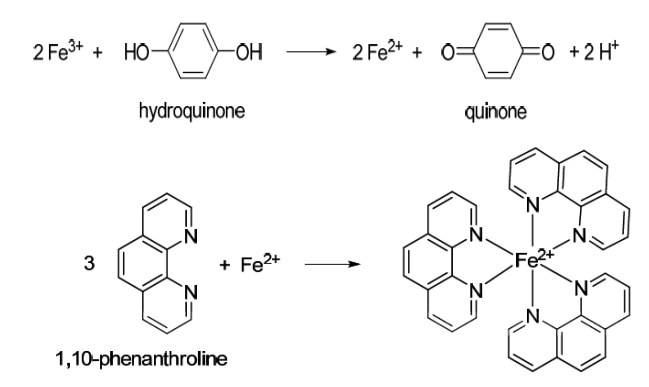

Figure 1: Reaction scheme for the formation of iron phenanthroline complex

\section{Results and Discussion}

Determination of $\lambda_{\text {max }}$ and calibration plot

The absorbance of the standard iron solution was obtained as a function of wavelength ranges from 440 to $550 \mathrm{~nm}$ and maximum absorbance $(\lambda \max )$ was obtained at $510 \mathrm{~nm}$ which is nearly matched with literature values (figure 2a) [20-21]. Keeping the 510 $\mathrm{nm}$ wavelength fixed, absorbance of several standard iron solutions $(0.4,0.8,1.2,1.6,2.0,2.4,2.8,3.2$, $3.6,4.0) \mathrm{ppm}$ were obtained for the preparation of the calibration plot (figure 2b). The Beer Lambert's law was found to be obeyed in the range of 0.4-4.0 $\mathrm{mg} / \mathrm{L}$ of iron (II) and thus obtained calibration plot was used for the quantification of iron in the different iron tablets.

\section{Determination of iron(II) in iron tablets}

Iron can be determined by using different tools viz atomic absorption spectrometry [22-24], high-performance liquid chromatography [23], and spectrophotometry [25], etc. Moreover, in spectrophotometric

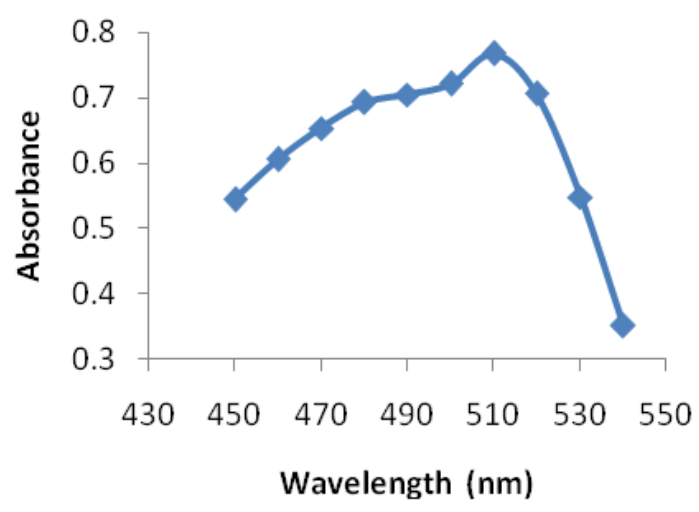

Figure 2a: Determination of $\lambda_{\max }$ for the estimation of iron 


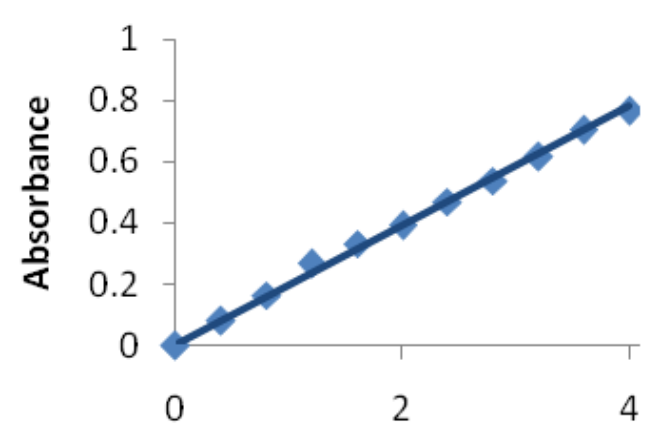

Concentration (ppm)

Figure 2b: Calibration plot for the quantification of iron

determination, varities of photometric reagents such as 1,10-phenanthroline (orange-red color complex), tiron (blue-color complex), thioglycolic acid (red-purple color complex) etc are used for the determination of iron [25].

Randomly collected commercial solid iron tablets were coded as samples (A, B, C, D, E, F, G, H, I, $\mathrm{J})$ and iron content in coded tablets was determined spectrophotometrically using 1,10-phenanthroline as a photometric reagent. During the work, triplet measurements were carried out for each tablet. The total amount of iron found in iron tablets from the calculations based on the calibration curve (figure $2 \mathrm{~b}$ ) as well as the claimed values from manufacturer companies are summarized in Table 1 and are shown in the bar diagram (figure 3 ).

The amount of iron content in each pharmaceutical sample is different though all have the claimed same amount of iron (100 mg per tablet) except sample $\mathrm{H}(50 \mathrm{mg}$ per tablet). The amount of iron content in sample A was found to be $104.64 \mathrm{mg} /$ tablet and

Table 1: Amount of iron found in different tablets by spectrophotometric method

\begin{tabular}{lllc}
\hline $\begin{array}{l}\text { Sample } \\
\text { code }\end{array}$ & $\begin{array}{l}\text { Iron content } \\
\text { per tablet/mg } \\
\text { (Label) }\end{array}$ & $\begin{array}{l}\text { Iron content } \\
\text { per tablet/mg } \\
\text { (this experiment) }\end{array}$ & $\begin{array}{c}\text { Relative } \\
\text { error } \\
\text { (\%) }\end{array}$ \\
\hline $\mathrm{A}$ & 100 & 104.64 & 4.43 \\
$\mathrm{~B}$ & 100 & 99.33 & 0.67 \\
$\mathrm{C}$ & 100 & 96.25 & 3.75 \\
$\mathrm{D}$ & 100 & 96.04 & 3.96 \\
$\mathrm{E}$ & 99 & 97.07 & 1.94 \\
$\mathrm{~F}$ & 100 & 97.48 & 2.52 \\
$\mathrm{G}$ & 100 & 98.71 & 1.29 \\
$\mathrm{H}$ & 50 & 48.02 & 3.96 \\
$\mathrm{I}$ & 100 & 102.2 & 2.15 \\
$\mathrm{~J}$ & 100 & 80.65 & 19.35 \\
\hline
\end{tabular}

$a=$ average value of three determinations for each sample that of a sample I was $102.2 \mathrm{mg} /$ tablet. Both values are higher than the claimed amount of iron in these iron samples. The iron content in iron samples B, C, $\mathrm{D}, \mathrm{E}, \mathrm{F}, \mathrm{G}, \mathrm{H}$, and $\mathrm{J}$ was found to be $99.33,96.25$, 96.04, 97.07, 97.48, 98.71, 48.02, $80.65 \mathrm{mg} /$ tablet respectively. The amount of iron content was found to be less than the labeled amount of iron in these eight samples.

Moreover, in the sample $\mathrm{J}$, the iron content was found to be $19.35 \%$ less than the labeled value by the manufacturer. This higher discrepancy may be due to the interferences of other components present in the sample as the sample $\mathrm{J}$ was a gelatinous capsule while others were in solid tablet form. Besides this gelatinous sample $J$, the observed results in this study were in agreement with the similar study for the determination of iron in iron tablets by a spectrophotometric method using 1,10-phenanthroline as a color developing reagent $[10,25,26]$. Observed discrepancies of iron content between experimentally determined and reported values by a company in the analyzed tablets were found to be within the error of this experimental method.

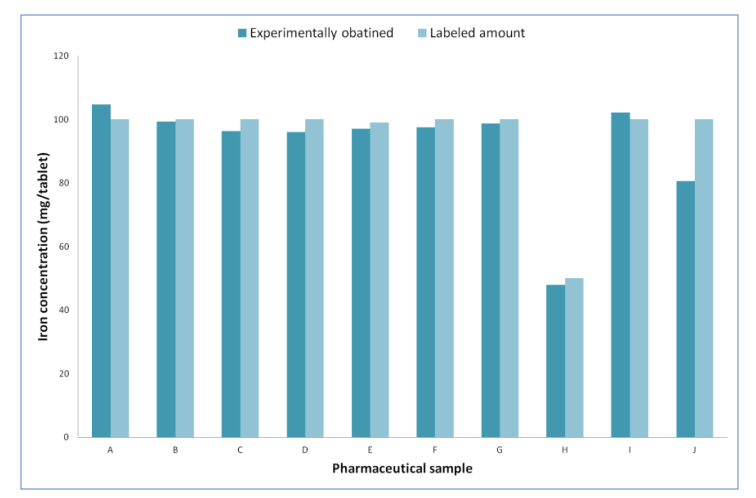

Figure 3: Comparative study of the labeled amount of iron by producer and experimentally observed iron content in different iron samples

\section{Conclusions}

The amounts of iron present in different iron tablets were analyzed by using 1,10-phenanthroline as a color developing agent. From the spectrophotometric method, out of ten samples, the total iron content of two samples namely A and I were found to be higher and the rest eight samples namely B, C, D, E, F, G, H, and J were found to be lesser iron content than the labeled amount by manufacturing companies. However, the observed discrepancies between experimentally obtained iron content and the labeled amount of iron content by the manufacturers were within the experimental error of this experimental method. 


\section{Acknowledgments}

The authors are thankful to the Central Department of Chemistry, Tribhuvan University for providing the necessary laboratory facilities to carry out this research.

\section{References}

1. A. B. Boxi, Facts about iron, livescience, 2017, accessed on August 2020, retrieved from https:// www.livescience.com/29263-iron.html.

2. P. A. Frey, and G. H. Reed, The ubiquity of iron, ACS Chemical Biology, 2012, 7(9), 1477-1481. (DOI: https://doi.org/10.1021/cb300323q).

3. Iron, Fact sheet for a health professional, National Institute of Health Science 2020, accessed on August 2020, retrieved from https://ods.od.nih. gov/factsheets/Iron-HealthProfessional.

4. F. Oliveira, S. Rocha, and R. Fernandes, Iron metabolism from health to disease, Journal of Clinical Laboratory Analysis, 2014, 28(3), 210218. ( DOI:10.1002/jcla.21668).

5. P. C. C. Oliveira and J. C. Masini, Sequential injection determination of iron (II) in antianemic pharmaceutical formulations with spectrophotometric detection, Analytical Letters, 2001, 34(3), 389-397. (DOI: https://doi. org/10.1081/AL-100102581).

6. A. U. Itodo, A. Usman, S. B. Sulaiman, and H. U. Itodo, Color matching estimation of iron concentrations in branded iron supplements marketed in Nigeria, Advances in Analytical Chemistry, 2012, 2(1) 16-23. (DOI: 10.5923/j. aac.20120201.04).

7. Iron-deficiency anemia, American society of hematology, accessed on August 2020, retrieved from https://www.hematology.org/education/ patients/anemia/iron-deficiency.

8. G. Moschonis, D. Papandreou, C. Mavrogianni, A. Giannopoulou, L. Damianidi, P. Malindretos, C. Lionis, G. P. Chrousos, and Y. Manios, Association of iron depletion with menstruation and dietary intake indices in pubertal girls: the healthy growth study, BioMed Research International, 2013, 1-8. (DOI: http://dx.doi.org/10.1155/2013/423263).

9. L. Hallberg, L. Hulthen, and L. Garby, Iron stores and hemoglobin iron deficits in menstruating women. Calculations based on variations in iron requirements and bioavailability of dietary iron, European Journal of Clinical Nutrition, 2000, 54 650-657.

10. A. Rajbhandari, A. Aryal, and S. D. Rajbhandari, Determination of iron in iron tablets by spectrophotometry and atomic absorption spectroscopy, International Journal of
Pharmaceuticals \& Biological Archive, 2013, 4(3), 435-438.

11. C. Cassata, What is anemia ? symptoms, causes, diagnosis, treatment, and prevention, Everyday Health, 2020, accessed on August 2020, retrieved from https://www.everydayhealth.com/anemia.

12. C. Camaschella, Iron-deficiency anemia, The New England Journal of Medicine, 2015, 37(2), 18321843. (DOI: 10.1056/NEJMra1401038).

13. N. J. Kassebaum, R. Jasrasaria, M. Naghavi, et al. A systematic analysis of global anemia burden from 1990 to 2010. Blood, 2014, 123(5), 615-624. (DOI:10.1182/blood-2013-06- 508325).

14. R. K. Chandyo, T. A. Strand, R. J. Ulvik, R. K. Adhikari, M. Ulak, H. Dixit, and H. Sommerfelt, Prevalence of iron deficiency and anemia among healthy women of reproductive age in Bhaktapur, Nepal, European Journal of Clinical Nutrition, 2007, 61, 262-269. (DOI: 10.1038/ sj.ejen.1602508).

15. J. M. Tielsch, S. K. Khatry, R. J. Stoltzfus, J. Katz, S. C. LeClerq, R. Adhikari, and R. E. Black, Effect of routine prophylactic supplementation with iron and folic acid on preschool child mortality in southern Nepal: community-based, cluster-randomized, placebo-controlled trial, The Lancet, 2006, 367(9505), 144-152. (DOI: https:// doi.org/10.1016/S0140-6736(06)67963-4).

16. V. R. Gordeuk, B. R. Bacon, and G. M. Brittenham, Iron overload: causes and consequences, Annual Review of Nutrition, 1987, 7, 485-508.

17. B. Lonnerdal, Excess iron intake as a factor in growth, infections, and development of infants and young children, American Journal of Clinical Nutrition, 2017, 106, 1681S-7S. (DOI: https:// doi.org/10.3945/ajen).

18. M. T. Alula, A. M. I. Mohamed, and A. A. Bekhit, Simultaneous spectrophotometric determination of iron (II) and copper (II) in tablets by chemometric methods, Thai Journal of. Pharmaceutical. Sciences, 2010, 34(3), 93-106.

19. Z. O. Tesfaldet, J. F. Staden, and R. I. Stefan, Sequential injection spectrophotometric determination of ion as $\mathrm{Fe}$ (II) in multi-vitamin preparations using1,10-phenanthroline as a complexing agent, Talanta, 2004, 64(5), 11891195. (DOI:10.1016/j.talanta.2004.02.044).

20. R. C. Atkins, Colorimetric determination of iron in vitamin supplement tablets. A general chemistry experiment, Journal of Chemical Education, 1975, 52(8), 550. (DOI: https://doi.org/10.1021/ ed052p550).

21. Vogel's Textbook of Quantitative Chemical Analysis, 5th Ed. Longmans Group UK Limited, 
1989, 691-692.

22. F. R. Adolfo, P. C. do Nascimento, G. C. Leal, D. Bohrer, C. Viana, L. M. de Carvalho, and A. N. Colin, Simultaneous determination of iron and nickel as contaminants in multimineral and multivitamin supplements by solid sampling HR-CS GF AAS, Talanta, 2018, 178, 231-236. (Doi:10.1016/j.talanta.2018.12.010).

23. F. M. Khokhar, T. M. Jahangir, M. Y. Khuhawar, M. S. Qureshi, M. I. Khaskheli and L. A. K. Khokhar, Spectrophotometric and liquid chromatographic determination of $\mathrm{Zn}(\mathrm{II})$, $\mathrm{Ni}(\mathrm{II}), \mathrm{Fe}(\mathrm{II}), \mathrm{Co}(\mathrm{II})$, and $\mathrm{Cu}(\mathrm{II})$ as metal chelates from vegetable and pharmaceutical samples using 3-hydroxy-5-(hydroxymethyl)2-methyl-4-pyridine carboxaldehyde-4-phenyl3-thiosemicarbazone as derivatizing reagent, Journal of Liquid Chromatography \& Related Technologies, 2019, 41(19-20), 1074-1081. (DOI: 10.1080/10826076.2019.1565830).
24. E. Canfranc, A. Abarca, I. Sierra, and M. Marina, Determination of iron and molybdenum in a dietetic preparation by flame AAS after dry ashing, Journal of Pharmaceutical and Biomedical Analysis, 2001, 25(1), 103-108. (DOI:10.1016/ s0731-7085(00)00487-8).

25. J. Jurgens, L. Paama, and I. Leito, The uncertainty of UV-Vis spectrophotometric and FAAS analysis for the determination of iron in pharmaceutical products, Accreditation and Quality Assurance, 2007, 12(11), 593-601. (DOI 10.1007/s00769007-0299-9).

26. D. J. Garol, Application of UV spectrophotometric method for estimation of iron in tablet dosage form, International Journal of PharmTech Research, 2012, 4(1), 309-310. 